\title{
FIRST Framework Design and Facilitate Active Deep Learner eXperience
}

\author{
Mohamed Bahgat ${ }^{1}$, Ashraf Elsafty ${ }^{2}$, Ashraf Shaarawy ${ }^{3}$, Tamer Said ${ }^{4}$ \\ ${ }^{1}$ Sega Group Founder \& CEO, Egypt/USA \\ ${ }^{2}$ Adjunct Assistant Professor, ESLSCA Business School \\ ${ }^{3}$ Research Centre Manager, Sega Group, Egypt \\ ${ }^{4}$ Senior Researcher, Sega Group, Egypt \\ Correspondence: Ashraf Shaarawy, Research Centre Manager, Sega Group, Egypt.
}

Received: June 4, $2018 \quad$ Accepted: June 28, $2018 \quad$ Online Published: July 4, 2018

doi:10.11114/jets.v6i8.3337 URL: https://doi.org/10.11114/jets.v6i8.3337

\begin{abstract}
Over the past decades, Learning \& Development has become an area of growing interest and constant research. As a result, there is an abundance of studies and models that target the development of educators. However, the professional development of educators should be built on a comprehensive framework of research-based instructional strategies that help train them on how to understand, experience, practice and leave a sustainable impact on learners. This paper presents our own "FIRST Framework", a holistic framework designed on the basis of renown models and theories, such as: experiential learning; Gamification and game-based learning; facilitative learning, 6Ds model, positive psychology, experience economy and neuroscience. It is an engaging framework that helps educators bridge theory and practice to create high-quality learning environment in their classrooms. FIRST Framework consists of 5 domains with 15 principles that help leave sustainable impact on learners through promoting Active Deep Learner Experience.
\end{abstract}

Keywords: active learning, deep learning, student experience, active deep learning, learner eXperience facilitation, learner eXperience design

\section{Introduction}

One of the ultimate goals of adult learning researchers and educators is to achieve transfer of learning, where the learner is willing and capable of transferring the knowledge and skills acquired in the classroom into practice in real-life situations. According to Leberman, McDonald and Dyle (2006) many educators consider transfer of learning as the most important outcome of their practice. Perkins and Salomon (1992) added that "Transfer is a key concept in education and learning theory because most formal education aspires to transfer" (p.3).

We view that Active and Deep learning are essential to achieve not only transfer of learning but also a memorable experience. To come to such conclusion, we encourage educators to incorporate variety of teaching and learning techniques which may lead to more positive learner experiences (Manthiou, Lee, \& Tang, 2011) and may achieve transfer of learning as suggested by Merriam and Leahy (2005), such as cooperative learning, role playing, writing, in class games and peer teaching which can promote active learning (Bonwell \& Eison, 1991), and can also promote deep learning (Yew et al., 2016).

As suggested by Freiberg \& Driscoll (2000), a comprehensive framework for educators' professional development should be built on research-based instructional strategies. This paper aims to introduce a framework that help the educators to design and facilitate a learning program that achieves a memorable and impactful learner experience through building on that framework according to his or her context and application. In FIRST framework, we build on the learner experience to facilitate the transfer of learning, this view is supported by Merriam and Leahy (2005) suggestion that the more authentic the learning experience, the more likely transfer will occur. Additionally, we believe that people don't learn from experience itself, rather they learn from reflecting on the experiences they encounter (Thiagarajan, 2004).

Our view of learner experience is drawn from both the experience economy introduced by Pine and Gilmore (1998), extended to learning and teaching arena by Moore and Bruce (2015) and total student experience introduced by Harvey, Burrows and Green (1992), which suggest that student experience does not only take place in the classroom but it is 
about a whole range of experiences that students are exposed to.

Our view revolves around helping educators live a complete active deep learner experience to be able to witness their self-transformation and acknowledge its impact, making it easier for them to adopt the same Active Deep learning approach in future learning events.

\section{Theoretical Background}

FIRST framework is a holistic one; it is based on other models and theories, such as: experiential learning by Kolb and Dewey; gamification and game-based learning; facilitative learning, 6Ds model, as well as positive psychology, experience economy and neuroscience. The theoretical influence for FIRST framework has two parts; the primary theoretical influence is the theories and models that influence the framework as a whole, while the secondary theoretical influence represents theories and models that affect some specific domains of the framework.

FIRST framework includes five main domains, and fifteen principles as shown in Figure (1). These principles act together in an integrated format; creating our Active Deep Learner eXperience approach.

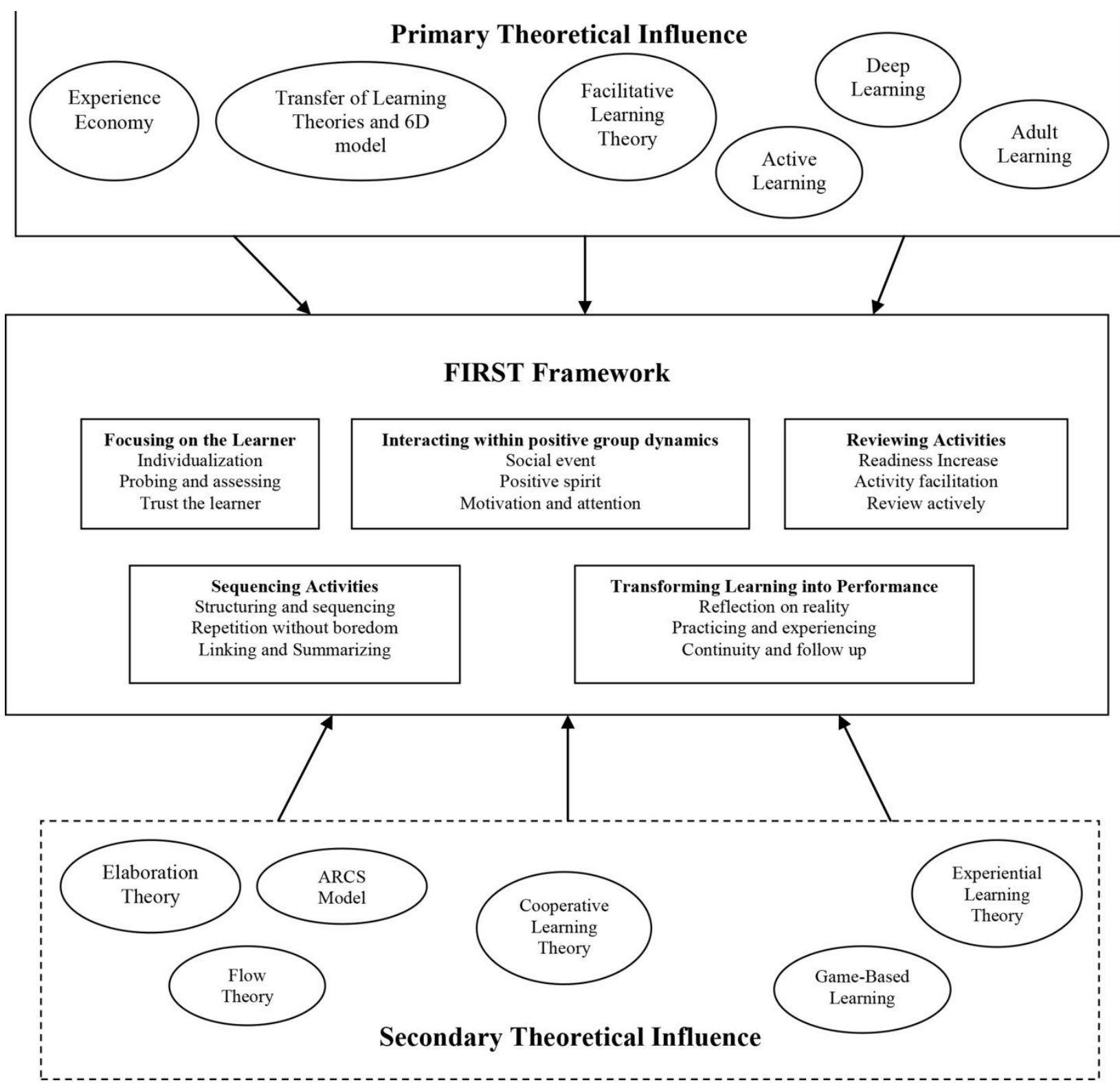

Figure 1. FIRST Framework and its theoretical background

\subsection{The Primary Theoretical Influence}

The primary theoretical influence of our FIRST framework consists of the theories that inspire the framework and its entire domains. 


\subsubsection{Experience Economy}

Pine and Gilmore (1998) proposed that experience is a fourth stage of economic offering besides the three economic offerings of: commodity offering which deals on commodities such as coffee beans, goods offering where manufacturers roast and grind the coffee beans, and service offering where restaurants serve our coffee. They contended that services have become commoditized in the same way those raw materials such as coffee beans. They argued that experience can be a distinct offering from service and should provide a memorable offering that remains with the customer for a long time, but in order to achieve this, the consumer should feel a sensation that result from participating actively. This requires highly skilled people, who can dynamically individualize each event according to the needs of the customers. Graham, Dezuanni, Arthurs, and Hearn (2015) argued that higher education should adapt to experience economy instead of providing a commoditized form of information. Pine and Gilmore (1998) described experience "as real offering as any service, good, or commodity" and "occurs when a company intentionally uses services as the stage, and goods as props, to engage individual customers in a way that creates a memorable event" (p. 98). They described experience as: "inherently personal, existing only in the mind of an individual who has been engaged on an emotional, physical, intellectual, or even spiritual level" (Pine \& Gilmore, 1998, p. 99).

We review that making the learner experience a memorable one, can help achieve transfer of learning; this view is supported to a great extent by Pine and Gilmore (1999) suggestion that participants of training may transfer the knowledge to their real-life practices if the training is enjoyable to them.

\subsubsection{Learner experience}

Learner experience is foundational concept in FIRST Framework; it is important to achieve the memorable and impactful experience as a means to achieve transfer of learning. We want to point out that the word "experience" has dual meaning in English language while some other languages such as German and Russian use two separate words for this dual meaning. In the German language for example, the word "Erfahrung" correspond to the English noun "experience" meaning the skills, practices, know-how and accumulated life knowledge that make up a human being (Gelter, 2010). On the other hand, the German word "Erlebnis" corresponds to the English noun "experience" as an encounter or event, as well as the English verb "experience" to indicate feelings, emotions, and what we live through (Gelter, 2010). In this paper, we mention experience in the form of Erlebnis as "Learner or Learning Experience" and experience in the form of Erfahrung as Previous Experience. We view learner experience as the result of emotional, physical, intellectual, or even spiritual levels according to Pine and Gilmore. Davachi, Kiefer, Rock, \& Rock (2010) in their AGES Model argued that emotions play an important role in both learning and memory construction; they reviewed that there is a high correlation between the emotional experience of an event and memories about it, which may lead to be better encoded in memory of the individual. A desirable experience can affect emotion, last long in the mind of the individual and consequently influence his or her behaviour (Manthiou et al., 2011).

In the educational context, Thomson, Grierson, Ball, and Mendibil (2008) as well as Benckendorff, Ruhanen, and Scott (2009) stated that Harvey, Burrows and Green (1992) are credited with first coining the term "total student experience" in the context of higher education, Harvey et al. (1992) stated that student experience "is not restricted to the student experience in the classroom but to the total student experience" (p.1). Benckendorff et al. (2009) argued that notions of the student experience are complex and has different aspects, they added that institutions have adopted the term student experience to denote teaching academic aspects, content and curriculum, learner activities, mentoring. They argued that learner experience is associated with learner engagement, satisfaction and retention.

\subsubsection{Transfer of Learning}

Thorndike and Woodworth (1901) defined transfer of learning as "a product of the learning process where something learned in one context is used to assist learning in another context" (as cited in Middleton \& Baartman, 2013, p. 2). Transfer can be viewed as application of learning gained in one context to another context (Gagne, Yekovich, \& Yekovich, 1993).

We agree with Cormier and Hagman (1987) argument that despite the terminology debate, the term transfer of training equates to the term transfer of learning. Goldstone and Day (2012) stated that "learning without transfer of what has been learned is almost always unproductive and inefficient" (p.149). Jefferson, Pollock, and Wick (2014) agreed with that by stating "It doesn't matter what they learned, or how well they mastered new skills; unless they are willing to make the effort to transfer and apply them, the learning is scrap" (p.79).

In FIRST framework we emphasize on the role of learning that affects the knowledge, skills and attitudes of the learner in a way that help making the transfer of learning, this is supported to a great extent by Subedi (2004) argument that transfer of learning is viewed as the degree to which learners apply knowledge, skills, and attitudes gained in one context to another. 


\subsubsection{Facilitative Learning Theory}

Carl Rogers and others have developed the facilitative learning theory. According to Laird (1985), the facilitative learning theory postulates that learning will take place when educator act as a facilitator of learning, by establishing a safe environment through which learners are exposed to new knowledge and experience and are allowed the space to reflect on their existing experiences. Miller (2001) reviewed that Rogers contended this focus will help learners to achieve self-actualizing and become self-directed individuals. He further explores Rogers' argument the educator should encourage learners to plan for their directions based on their own interests.

FIRST Framework proposes that the role of an educator is not just transmitting knowledge but also facilitating the learning, which will result in an effective learner experience, as suggested by Liasidou (2016), and a better transfer of learning as suggested by Hung (2013).

\subsubsection{Active Learning}

Active Learning is defined as "instructional activities involving students in doing things and thinking about what they are doing" (Bonwell \& Eison, 1991, p.5). They propose that for the learners to be active learners, they should not only just listen but they should also write, read, discuss and solve problems. FIRST Framework stresses on active learning as a way to achieve the transfer of learning as suggested by Subedi (2004), who states that "Active learning is an important criterion for transfer to occur" (p.593). Additionally, we argue that using active learning may result in enhanced student experience as suggested in a study by Georgiou and Sharma (2014), where they showed that using an active learning technique may have better learner experience.

\subsubsection{Deep Learning}

Godor (2016) reviewed that deep and surface learning are derived from the work of (F. Marton and R. Säljö, 1976). Biggs and Tang (2011) asserted that deep approach encourages learners to seek underlying meanings, relate new knowledge to prior experience, analyse and evaluate the new knowledge.

Laird, Shoup and Kuh (2005) emphasized on the importance of deep learning by suggesting that learners who use this approach tend to retain, integrate and transfer information at higher rates. They also added that deep learning is associated with more enjoyable learning experience compared to the surface learning approach.

\subsubsection{Adult Learning Theory}

Malcolm Knowles has argued that people should be treated as adults when they behave in an adult manner. Knowles (1984) identified five assumptions about adult learners. Changes in self-concept, which happens when a person grows and matures, and then transform from being dependant individuals who rely on others to satisfy their needs into independent individuals who are self-directed and capable of making decisions as well as caring for themselves. The role of experience, which takes into consideration that every individual grows up with an accumulated wealth of experience that becomes a resource for learning as well as providing a frame of reference to which they can relate and connect their new learning. Readiness to learn, which suggests that adult learners are more aware of the importance of development and self-improvement; therefore, they are more willing to learn and perceive learning as a means to elevate their social status and perform their social roles.

Orientation to learn, showing that adult learners are more inclined towards immediate application of learning rather than postponed application. And finally, Motivation to learn, explaining that as a person matures, his/her motivation to learn become more intrinsic.

In FIRST framework, we build on the Adult Learning to engage the learners and to let them live the experience, which is supported to some extent by McDonald (2011) suggestions that adult learning theory can help to assist adults in transferring their learning into performance.

\subsection{The Secondary Theoretical Influence}

The secondary influence is a set of theories and models that affect some specific domains of the Framework, in the section below we will review those theories and models and will point out which of them is related to which domain in the next section.

\subsubsection{Elaboration Theory}

The Elaboration Theory, which was proposed by Reigeluth and Stein (1983), is an instructional design model that aims to help instructional designers structure and sequence content to achieve optimal learning outcomes.

The Elaboration Theory suggests a zoom-lens analogy to the instruction design where the studied topic should be organized in increasing order of complexity where the learners will begin the lesson with a big picture "zoom out" of the topic under study, then narrow it down to a more focused and simplified version "zoom in", after that learners are 
asked to look back at the larger picture "zoom out again". This will help the learner to develop a meaningful context into which subsequent elements of the topic and required skills are synthesized. In FIRST framework we encourage the educators to structure the learning event in a way that help learners to grasp the big picture and to link it with the subject details.

\subsubsection{Flow Theory}

According to Csikszentmihalyi (1975), Flow describes a state of complete absorption or engagement in an activity and refers to the optimal experience. During the optimal experience, a person is in a psychological state where he or she is extremely involved within the activity that nothing else seems to matter. An activity that produces such experiences is so pleasant that the person may be willing to do something for its own sake, without being concerned with what he will get out of his action.

Csikszentmihalyi (1993) suggested that there are eight dimensions of the flow experience; achieving complete concentration on the task at hand; clarity of goals and reward in learner's mind as well as immediate feedback; the experience should be intrinsically rewarding, has an end itself, effortlessness and ease; a balance between the level of challenge and personal skill; actions and awareness are merged; losing self-consciousness; learner's feeling of control over the task; time distortion by changing the pace through speeding up or slowing down of time. FIRST Framework encourages educators to design their activities in a way that help the learners be completely immersed in those activities which can help them achieve a memorable learner experience.

\subsubsection{ARCS Model of Motivational Design}

According to Keller (1987), The ARCS Model of motivation suggests effective ways of understanding and identifying the major influences of learning motivation and solving problems that face educators and instructional designers. The model describes four domains; Attention, Relevance, Confidence, and Satisfaction, along with their strategies that are suggested to motivate learners.

Attention is an element of motivating learners towards the ideas and concepts that they should learn. Attention could be gained in three ways; the first one is perceptual arousal using surprise, uncertain situations; the second is inquiry arousal through stimulating learner's curiosity using some strategies of problem solving or challenging questions; the third is variability using different methods in presenting material such as videos, role plays, short lectures or discussion groups to address individual different learning styles.

Relevance comes from the content to be conducted as well as the way of conducting. This can be achieved by some strategies including; informing the learners how the new learning will use their existing experiences and skills, illustrating what the subject matter will do for them today and what the subject matter will do for them tomorrow.

Confidence is a challenge for educators in generating and maintaining motivation is to help learners to develop their confidence by helping them understand their abilities for success. If they feel they cannot meet the objectives, their motivation will decrease. Provide objectives and prerequisites; ensure the learners are aware of performance requirements and evaluation criteria; provide feedback and support internal attributions for success.

Satisfaction, which includes strategies and practices that can be intrinsic or extrinsic and to make learners feel good about their achievements, also learning should be satisfying or rewarding, whether it is from a sense of achievement, praise, or entertainment.

FIRST Framework urges educators to design and facilitate the learning in a way that incorporate the relevance of the content, curriculum and context, that will lead to active deep learner experience to help learners increase their motivation and attention levels. This view is supported by Moore (1989) proposition that the interaction between the learner and content can contribute to a positive learning experience.

\subsubsection{Cooperative Learning}

According to Johnson and Johnson (2002), cooperative learning builds on the work of Kurt Lewin about group dynamics. Cooperative learning is defined as "group learning activity organized so that learning is dependent on the socially structured exchange of information between learners in groups and in which each learner is held accountable for his or her own learning and is motivated to increase the learning of others" (Olsen \& Kagan, 1992, p.8)

Through concepts of cooperative learning, adults can enhance their knowledge and skills in a shorter time compared to working individually. By sharing their workload and disseminating information more quickly, adult students may realize their goals more readily and thoroughly (Johnson, Johnson \& Smith 1991).

Kagan (2011) explains that cooperative learning consists of what he defines as PIES, which is an acronym that stands for Positive Interdependence, Individual Accountability, Equal Participation, and Simultaneous Interaction. 
In FIRST framework we argue that using cooperative learning strategies can enhance the transfer of learning. This is supported by Mikulecky, Albers and Peers (1994) suggestions that transfer of learning may be effective through the use of cooperative learning groups. Regarding the learner experience, Hassanien (2006) reported that his study supports the findings of previous research into group work suggesting that the students' experience is generally positive. Also, Farrell and Farrell (2008) reported that "cooperative learning as a student focussed pedagogical approach provides educational satisfaction" (p.52).

\subsubsection{Gamification and Game Based Learning}

Karl Kapp described gamification as "an emergent approach to instruction which facilitates learning and encourages motivation through the use of game elements, mechanics and game-based thinking" (Reigeluth, Beatty \& Myers, 2017, p.356). The importance of gamification can be seen according to Al-Azawi, Al-Blushi \& Al-Faliti (2016) that when students enter the flow state in playing, their concentration is elevated. Game can be defined as an activity that must have the following characteristics; fun where the chosen activity should be cheerful; separation which is restricted in time and place; uncertainty where the outcome of the activity is unexpected; governed by rules where the activity has rules that are different from everyday life (Al-Azawi et al. 2016). They also added that an educational game should be designed and used for learning and should combine the elements of fun and educational concepts to increase student's motivation and engagement.

According to Bodnar and Clark (2014), game-based learning can influence learners to the transfer of learning and may lead to a more positive classroom environment and student experience.

\subsubsection{Experiential Learning}

Experiential learning is the process of learning through grasping experience then transforming it and is more specifically defined as "learning through reflection on doing" (Felicia, 2011, p.1003).

Kolb (1984) called the theory "experiential" in order to emphasize on the central role of learner's experience in the learning process. Kolb suggested that the process of learning has two phases which are perceiving and processing. In the perceiving phase, people approach reality differently, either by feeling and sensing what they are exposed to or by thinking it through. Perceiving alone doesn't mean learning and here comes the second phase which is the processing phase, people tend to process information and experience differently, while some prefer to watch and reflect, others prefer doing by acting on the new information and experiencing it right away. Kolb emphasized that for the learning process to be effective, individuals should go through a complete cycle of four stages, the first stage is having a concrete experience, the second one is reflecting on that experience followed by third stage of constructing abstract concepts through analysis and conclusions which leads to the fourth stage of testing hypothesis in similar situations. Gardner and Korth (1997) stated that "individuals can use Kolb's experiential learning cycle to enhance the transfer of learning from one situation to another" (p.48). Moreover, Pine \& Gilmore (1998) explained that learner is immersed in the experience when he performs an experiential learning activity.

\section{Methodology}

Within our methodology developing this paper, we employed more than one of the main methodological approaches rooted within research methods. First, we used systematic approach as a methodology to collect and to summarise all possible empirical evidence and supporting scholarly papers and conclusions to consolidate using synthesising approach a possible scientific answer to our suggested framework, Strike and Posner (1983) defined synthesis as an activity in which separate parts are combined or integrated into a whole (as cited in Noblit \& Hare, 1988). Then we also use the meta-analysis approach, however the meta-analysis might be used in two different possible approaches; one of the well-known approaches of meta-analysis is quantitative. Within our research for this paper we used qualitative meta-analysis, as we conducted rigorous review on using qualitative data collection. Gathering primary qualitative findings from scholarly publications related to our framework. Both systematic review and qualitative meta-analysis helped us to develop and to formulate such methodology that generates our FIRST framework.

Figure (2) illustrates systematic approach and meta-analysis as well as the process of using each of them and how we integrated both outcomes from the systematic review and meta-analysis within our research methodology. 


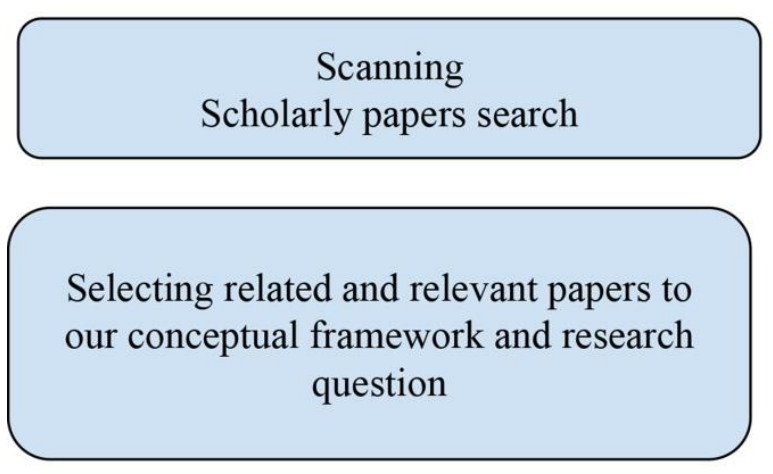

\section{Identifying \\ Professional practices}

\section{Comparing between scholarly selected science and related matching professional practices}

\section{Clustering comparisons within coherent homogeneous groups}

Integrating both clusters of science and related professional practices with our conceptual framework

\section{Generating the final concluded FIRST framework.}

Figure 2. Synthesizing Methodology to generate FISRT Framework

As demonstrated by Figure (2), we synthesized our FIRST framework through the review of the scholars and researchers literature and professional practices regarding the learning and development and then we have selected the relevant researches which contribute to the different aspect of the framework that we propose as well as the practical models that address the issues of achieving the transfer of learning, we compared and contrasted these scholarly articles and clustered their main concepts to come up with our synthesized framework.

\section{Data Analysis; Formulating FIRST Framework}

The five domains of FIRST act as layers each of them builds on the previous domain and adds on to it, all the principles integrate with each other to form the Active Deep Learner experience. We use the term "trip" to describe the face-to-face learning in the training room.

\subsection{Focusing on Learner Behaviour}

Focusing on the learner's behaviour throughout the trip, and how the educator interacts with every individual; along with activities that can be done to help the learner feel the experience is unique and individualized. The focus of this domain is on every learner and not the whole group of learners, by every learner we mean his/her learning curve through probing and assessing previous knowledge, feelings and learner experience. This domain builds on facilitation theory and adult learning theory by encouraging educators to facilitate learners to use their previous experience to construct their own learning.

\subsubsection{Individualization}

Individualization revolves around making the learning experience unique for each and every learner whenever possible; this includes building direct relation with every individual throughout the learning trip. The designer's role here is to 
include activities that help make the experience more intimate and personal to cater for individual needs and objectives without disturbing the day flow. Our view of Individualization agrees to some extent with Heathers (1977) definition of Individualization as "instruction consists of any steps taken in planning and conducting programs of studies and lessons that suit them to the individual student's learning needs, learning readiness, and learner characteristics or learning style" (p.342). It may be hard to apply individualization with all learners all the time during the trip, nevertheless, being conscious about personal variations will help to individualize the learners' experience. In support of this view, Heather (1977) also states that "Individualization must not be viewed as all-or-none. It can exist in all degrees from ignoring student differences most of the time to continually giving explicit attention to each student's special needs, readiness, and learning style" (p.342).

We argue that individualization affects the transfer of learning; this view is supported by Clark and Voogel (1985), who viewed that individual differences such as ability, prior knowledge, and expectations affects the level of transfer. According to Chang (2013), the interaction between the learner and the educator can increase the learner's satisfaction with the whole learning experience.

\subsubsection{Probing and Assessing}

In FIRST, if the educator is not presenting, he is either probing or assessing. Probing refers to the activities in which the educator scans the learning progress to keep track of participants learning with the purpose of providing feedback. Hung (2013) emphasized the role of probing to achieve transfer of learning where he encouraged educators to probe learners' knowledge deeply, and do not interject content or provide direct answers to questions.

Assessing is the process to check whether there are any gaps in learners' understanding or even misconceptions that may hinder new learning, educators use different opportunities to measure the learning outcomes and the overall learners' experience.

According to Willingham (2009), continuous assessment is necessary; since the longer students carry a misconception the harder it will be to correct it.

Probing and assessing should be done in a safe environment. Camp (2012) stressed on the importance of safe environment as a means to achieve transfer of learning by inviting educators to make their classrooms a safe environment where learners are not fearful of trying out new learning or making mistakes and learning from those mistakes when learners feel safe and valued they more likely to be engaged in learning.

\subsubsection{Trust the Learner}

Adults like to be given the opportunity to use their existing knowledge and experience and apply it to their new learning experiences. Knowles (1984) suggests that as a person matures, she accumulates a growing reservoir of experiences that become an increasing resource for learning. Adult learners resist learning or authoritative style of teaching when they feel others are imposing information, ideas or actions on them (Grow, 1991). Through FIRST framework, we encourage educators to overcome this authoritative style using three different strategies: first, we invite them to pull appropriate content from learners whether its previous experiences, thoughts, or feelings rather than pushing the knowledge or experience from the educators, second, we encourage them to allow the learners to take partial control on purpose to participate freely in different activities, and third we encourage educators to show interest in the learners and value their participation. This is supported by Estes (2004) recommendation to educators to let the students take more control of the conversation, talk freely.

Wohlfarth et al. (2008) stated that in student-centred approach "it seems that students can perceive whether professors inherently trust them, and that they predominantly respond to this trust in a positive way" (p.70). Thompson, Ngambeki, Troch, Sivapalan and Evangelou (2012) suggested that student-centred approaches improve transfer of learning from classroom settings to new situations.

According to Sankar and Wu (2015), when educators allow learners to have control for their activities this will create positive learning experience.

\subsection{Interacting Within Positive Group Dynamics}

This domain builds on group dynamics and cooperative learning, we focus on the interaction between learners. After we focused on the experience of each learner; we now intend to make every group a unique experience. This means the same learner can have different experience if she interacts with different group. Liasidou (2016) argues that interaction of class mates and social groups has greater effect on the students' experience. Merriam and Leahy (2005) suggested that group discussions may help individuals to be aware of their knowledge limits and evaluate the prospects of its transfer to new situations. 


\subsubsection{Social Event}

Reder and Klatzky (1994) stated that "learning is fundamentally a social activity" (p. 5). As claimed by Svinicki (2004), learners' engagement in a course is influenced by level of which the class becomes a community of learners. This principle is significant for breaking the ice and bonding students to create an interactive and safe environment that serves as the foundation for collaboration and integration between the educator and the learners and among the learners themselves. The most effective groups ensure the emotional security of their members and it is the educator role to provide this safe environment (Andritsakou \& Kostara, 2016).

We previously mentioned the importance of safe environment for probing and assessing and this shows how the principles of FIRST interact and integrate with each other.

When learners interact together in a group they can achieve better learning results by exchanging their knowledge and experience, this agrees with Andritsakou \& Kostara (2016) suggestion that cooperative learning enhances learning effectiveness and team productivity, compared to competitive learning.

Barnett and Ceci (2002) suggested that group works such as group reasoning can result in fruitful transfer and generation of joint insights. Nicholson (2012) argues that when educators facilitate learners to engage with each other this may lead to greater learning experience. The positive social relationships between learners can lead to greater learning experience (Davachi et al., 2010)

\subsubsection{Positive Spirit}

Anderson and Brocket (2008) reviewed that the focus of positive psychology on human strengths could benefit adult education's goals for helping learners to develop deeper understanding of their learning experiences. They also added that it is important for educators to pay more attention of how their feedback can affect adult students and positive psychology can offer some insight into those areas.

In Positive Spirit principle we encourage educators to use positive and constructive feedback which can help learners become more motivated to interact with a sense of belonging to the learning experience. Anderson and Brocket (2008) also contends that educator can have a great effect on learners by identifying their strengths and using more positive language to explain negative feedback. Moreover, we believe that educator-learner positive interactions, insights and sense of humour are key factors in promoting active learning and creating a joyful learning environment. Story (1985) supported that by suggesting the educator to displays a sense of humour which was found to be one of the key factors in successful teaching. Merriam and Leahy (2005) argued educator's negative feedback to learners may result in less learning and less transfer.

Garza and Salcedo (2015) argued that positive emotions in the classroom can help for memorable learning experience while negative emotions can lead to disengagement from their class and learning.

\subsubsection{Motivation \& Attention}

This principle builds on Keller ARCS model where he suggested that attention plays important role for motivating learners. Learners should keep a steady level of focus and attention throughout the whole learning even for maximum benefit. Therefore, educators should take the proper actions to raise their attention levels and re-engage them in case they lost focus. We encourage educators to include physical activities like energizers to change learners' status because this can help them regain their attention and get them ready to pursue learning. This view is supported by Willis (2007) suggestion that educators should encourage students to do any pleasurable activity that gives the Amygdale a chance to cool down and the neurotransmitters time to rebuild. When educators increase the learner's attention with a greater focus on their motivation, help learners to have better learning experiences (Davachi et al., 2010).

Sogunro (2015) suggested that motivation has a great effect to sustains effective learning. We believe that in order for learners to be active they should be motivated through the whole learning trip. Wlodkowski (1999) suggested that if a person is motivated he may achieve better performance and outcomes than the less motivated person. Moreover, Merriam and Leahy (2005) suggested that motivation is a key factor to successful transfer of learning.

\subsection{Reviewing Activities Within RAR}

This domain builds on Kolb experiential learning. We view that learning activities are important for adult learners. RAR stands for "Readiness increase, Activity facilitation, Reviewing actively", which is a model we developed; it focuses on the full experience of the activity, how to increase participants' readiness and how to review the activity to deepen the learning. We view the day flow as a chain of activities each activity is RAR unit by itself. The Event Design and facilitation is a scenario of a variety of activities linked together through the timeline with a smooth transition between the RAR. Doyle (2006) supports our view by stating that "the basic unit of classroom organization is the activity" (p.101). 


\subsubsection{Readiness Increase}

We describe readiness as the preparation for learners to participate in the activity by increasing their attention to engage in it. Educators should pay attention to arrange the learning environment in a way that serves the learning outcomes they are intending to attain from this activity to support adult learners' participation, because their motivation is more vulnerable than that of younger learners (Wlodkowski, 1999).

Readiness can be in the form of mini presentation for the activity instructions; preparation of tools, gradual activities, emotional and mental readiness which leads to maximum engagement, Wlodkowski (1999) supports this view by advising educators to give clear instructions about how to do the learning activity; provide a timeline, start with simple activities such as think-pair-share and break the learners into groups.

\subsubsection{Activity Facilitation}

The educator plays an important role during the activity with the group, this view is supported by Barron (2003) that the potential of the group to facilitate learning is affected by the quality of the interaction within the group which may be affected by the skills of the educator. In the Activity facilitation we see the role of the educator agrees to great extent with what Hazzan, Lapidot and Ragonis (2011) suggestion that the educator role in this stage is to circulate between different groups offering guidance and help whenever needed. Hazzan et al. (2011) further explained that the type of guidance or support offered by educator should allow students to own their learning and find out the answers themselves, and it should not exclude or prevent any opinion or point of view.

\subsubsection{Reviewing Actively}

Review Actively principle is where the actual learning takes place after learners get exposed to the activity. Reviewing should take enough time as it helps students acknowledge the changes happening regarding their thoughts, feelings, attitudes and the reflections they made during that experience of the activity. We build the reviewing actively based on Greenaway debriefing model which is reviewed by Nicholson (2012), the model consists of four-stage active reviewing sequence starts with; learner experience to reflect and discuss the activities that occurred; then to express their emotions that they felt during the process; after that learner examine to mentally detach from the experience to consider, more holistically, what happened and how well everything went, finally, learners explore how the activity can connect into the real world. Greenaway model can be incorporated with the three clusters of questions proposed by Schoel, Prouty and Radcliffe (1988) model for how to ask debrief questions: "What? So What? and Now What?" to help learners construct meaningful learning through answering and hearing each other answering some questions that are guided by the educator. The "What" question helps students recall what they experienced academically, socially and emotionally during the activity, the "So What" question urges students to think of the objectives or why they experienced that activity and what they learned from it, and the "Now What?" question puts the learning into performance actions and helps student reflect on how they could apply their learning inside the class on the daily life practices, people don't learn from experience by itself rather they learn from reflecting on it (Thiagarajan, 2004).

Pivec (2011) and Nicholson (2012) both argued that debriefing activities make the learning experience effective and successful. Nicholson (2012) also suggested educators should encourage learners to integrate experience they gained through the activity with concepts and applications that can be transferred to the settings outside the classroom through the debriefing for training activities.

\subsection{Sequencing Activities}

Because we believe that the learning trip is a complete experience unit by itself, we encourage educators to fully consider the emotional and mental statuses of the learners along the whole day. Sequencing is not just the matter of sequencing group of learning activities along the day flow, but it is also for keeping the participants engaged all the time along the learning trip in order to achieve deeper and more sustainable impact. The main purpose is to sequence the activities and the day flow in a way that helps the participants be in the "flow" status. That's what drives us to visualize the day flow as a chain of activities each activity is RAR unit by itself. The Event Design and facilitation is a scenario of a variety of activities linked together through the timeline with a smooth transition between the RAR.

In this domain we draw on two theories in education namely the elaboration theory of Reigeluth and the flow theory of Csikszentmihalyi. According to Reigeluth (1999), there is a need for new ways to sequence instruction as a consequence of the paradigm shift from educator-centred instruction to learner-centred instruction. Reigeluth and Stein (1983), proposed the Elaboration Theory, as an instructional design model that help prepare and sequence content in a way that help to achieve learning outcomes. It is not enough that the content is well structured, it is equally important that the sequence of these activities is within the flow of each learner. Csikszentmihalyi $(1975,1993)$ supports our view where flow describes a state of complete absorption or engagement in an activity and refers to the optimal experience. 
During the optimal experience, a person is in a psychological state where he or she is so involved with the goal-driven activity that nothing else seems to matter.

\subsubsection{Structuring and Sequencing}

One of the most important issues in the application of learning theory is sequencing of instruction and activities which can affect the way information is processed and retained.

Toohey (1999) suggested that adult learners are motivated when learning activities are structured and sequenced; this shows that how this principle affects the Motivation and attention principle which indicates that the principles of FIRST integrate and interact with each other. Cooley and Glaser (1969) and Weisgerber (1971) argued that some programs may achieve transfer by carefully organizing and sequencing related instructional events (as cited in Royer, 1978). Liasidou (2016) suggested that educators should make the learning experience more active and immersive to make learners more motivated.

\subsubsection{Repetition Without Boredom}

Repetition helps students breach the gaps that occur in their understanding as well as helping them create stronger connections between different concepts. Rosenshine (2010) stated that students need extensive training on materials and extensive practice in order to develop a well-connected network of ideas in their long-term memory. The argument has been always on how educators could repeat learning without students getting bored. In FIRST, we propose that educators can use different enjoyable repeating techniques when delivering content to and encourage learner to actively repeat learning through different ways.

Davachi et al. (2010) suggested a 'spaced repetition', which combines repetition of new information, in a spaced manner, plays a role in building long-term memory.

\subsubsection{Linking and Summarizing}

It's the principle in which educators summarize learning outcomes, concepts, as well as linking participants' comments to the different parts of the learning day. This principle helps learners feel that knowledge is constructed, arranged and linked in a way that helps them remember and grasp the whole picture of the learning done during the day. This goes along with what Story (1985) stated that educators should help students be aware of the interrelationships between various ideas and lessons. According to the Elaboration Theory, we encourage educators and learners to have summaries of the content, the educator should encourage the learners to summarize what they have already learned and provide them with an overview of all previously learned steps at the end of each lesson.

\subsection{Transforming Learning Into Performance}

This domain deals with how to transfer the learning into action, and in FIRST, we believe that the learning transfer should start from within the classroom. So, this domain focuses on what activities and actions can be done within the training room that would help the learner keep an eye on the practice and the learning transfer, as well as helping in the follow up/mentoring phase which may take place after the trip.

\subsubsection{Reflection on Reality}

The main purpose of activities in FIRST is to invite learners to reflect on their reality in order to think about future applications. By reality, we mean three-time spans: previous, current, and future. For that, the activities have to be relevant to the learners' context and the educator should call learners to suggest future directions on improving their practice. According to Sogunro (2015), learners are interested in learning experience which is relevant and applicable to their requirements. Schwarz (2005) commented that the educator should also work as a coach who guides his learners towards improving their performances by allowing them to reflect on their behaviour and thinking processes. According to Gardner and Korth (1997), when educator provide specific time for reflection, integration of new learning and facilitate a discussion about linking the learning experience to the learners' work setting, this may increase transfer of learning. We view that reflection on reality can have better active deep learner experience.

\subsubsection{Practicing and Experiencing}

It is very essential to apply the learnt knowledge and skills during the learning trip. Apps (1991) stated that "Most adult learners have a practical reason for their learning, they want to learn something that they can apply immediately" (as cited in Sogunro, 2015, p. 29). This practice should be coupled with positive and constructive feedback that offers the learners directions on how to improve in order to make this learning permanent. In education, the importance of practice and experience is strongly highlighted. For example, Rosenshine (2012) stressed the importance of practice when learning something new. 
Salas and Cannon-Bowers (2001) arguing that transfer of learning can be realized when the learning event is designed to provide learners with real opportunities to practice what they learnt and receive feedback.

\subsubsection{Continuity and Follow Up}

Learning doesn't end in the classroom; what really matters is the continuity of learning after the training is over. Therefore, it is very essential to design and facilitate a space where learners can think of how to continue this learning, the action items they will take, let them think who can help them, the extra knowledge they may need to acquire after the learning event. In FIRST we encourage educators to invite the learner to develop an action plan for what they should do. This aligns with Martin (2010) suggestion that action plans are documents prepared by learners during or immediately after the learning event in which they describe how to implement learned skills outside the classroom settings. Martin (2010) suggested that the importance of developing this kind of plans is that it encourage learners to use both cognitive and behavioural components of the learning, where the learners are engaged cognitively in concepts and relationships, also it engage them behaviourally to describe the actions that they should take, evaluate their impact on the real-life situations. Merriam and Leahy (2005) suggested that using action planning at the end of training can strengthen the transfer of learning.

\section{Conclusion}

The purpose of this study is to introduce a new comprehensive framework that creates a memorable experience for the learner to live and go through, which helps in facilitating the transfer of learning. This framework is drawn from many learning theories and models; the framework aims to make the learner experience memorable, deep and sustainable. To address that, our proposed framework consists of 5 domains and each domain contains 3 principles, the first domain Focusing on the learner and aims to make a unique learner experience to each individual and to build the ownership of learning in the eyes of the learner to be able to transfer his learning during and after the training. The second domain is Interacting within positive group dynamics which addresses the notion of the whole is greater than the sum of each individual, it is through group dynamics and cooperative learning that learning and generation of new ideas can take place to build more knowledge to every member of the group. The third domain "Reviewing Activities", aims to immerse the learners in the activities of the learning, where we can keep the learner active during the learning trip, it also through the reflection that we can deepen the learning and internalize it, also to stress on the more important ideas of the learning outcomes. The fourth domain "Sequencing", guides learning designers and educators through designing their learning events and experiences with the appropriate structure that smoothly takes the learner step by step towards the learning outcomes and to make the sequence active to achieve the flow state of the learners by immersing them in the learning experience. At the end comes the fifth domain "Transforming" which is the gate that leads from the small training room to the wide and endless space of applying knowledge, skills and attitudes that the learner gains from the training to be able to transfer learning into performance.

Table 1.5 domains and 15 principles of FIRST Framework

\begin{tabular}{|l|l|}
\hline \multirow{4}{*}{ Focusing on Learner Behaviours } & Individualization \\
\cline { 2 - 3 } Interacting within positive group dynamics & Probing and assessing \\
\cline { 2 - 3 } & Trust the learner \\
\hline \multirow{4}{*}{ Reviewing Activities Within (RAR) } & Social event \\
\cline { 2 - 3 } & Positive spirit \\
\cline { 2 - 3 } & Motivation and attention \\
\hline \multirow{5}{*}{ Sequencing Activities } & Readiness Increase \\
\cline { 2 - 3 } & Activity facilitation \\
\cline { 2 - 3 } & Review actively \\
\hline \multirow{5}{*}{ Transforming Learning into Performance } & Structuring and sequencing \\
\cline { 2 - 3 } & Repetition without boredom \\
\cline { 2 - 3 } & Linking and Summarizing \\
\hline & Reflection on reality \\
\cline { 2 - 3 } & Practicing and experiencing \\
\cline { 2 - 3 } & Continuity and follow up \\
\hline
\end{tabular}




\section{Future Research}

The proposed framework should be examined using empirical data, so we propose more research to be carried out to test the validity and effectiveness of FIRST framework.

\section{References}

Al-Azawi, R., Al-Blushi, M., \& Al-Faliti, F. (2016). Educational gamification vs. game based learning: Comparative study. International Journal of Innovation, Management and Technology, 7(4), 131-136.

Anderson, M. N., \& Brockett, R. G. (2008). Is there a Place at the Adult Education Table for Positive Psychology?: Theorizing from the Literature, Adult Education Research Conference.

Andritsakou, D., \& Kostara, E. (Eds). (2016). The Role, Nature and Difficulties of Dialogue in Transformative Learning. Proceedings of the 2nd Conference of ESREA's Network "Interrogating Transformative Processes in Learning and Education: An International Dialogue". Athens, Greece: ESREA \& Hellenic Adult Education Association.

Barnett, S. M., \& Ceci, S. J. (2002). When and where do we apply what we learn?: A taxonomy for far transfer. Psychological Bulletin, 128, 612-637. https://doi.org/10.1037/0033-2909.128.4.612

Barron, B. (2003). When Smart Groups Fail, Journal of the Learning Sciences, 12:3, 307-359. https://doi.org/10.1207/S15327809JLS1203_1

Benckendorff, P., Ruhanen, L., \& Scott, N. (2009). Deconstructing the student experience: A conceptual framework, Journal of Hospitality and Tourism, 16(1), 84-93. https://doi.org/10.1375/jhtm.16.1.84

Biggs, J., \& Tang, C. (2011). Teaching for Quality Learning at University. SHRE and Open University Press.

Bodnar, C. A., \& Clark, R. M. (2014). Exploring the impact game-based learning has on classroom environment and student engagement within an engineering product design class. In Proceedings of the Second International Conference on Technological Ecosystems for Enhancing Multiculturality (pp. 191-196). https://doi.org/10.1145/2669711.2669899

Bonwell, C., \& Eison, J. (1991). Active learning: Creating excitement in the classroom (ASHE-ERIC Higher Education Report No. 1). Washington, DC: George Washington University.

Camp, D. (2012). Here, there and anywhere: Transfer of learning. Critical Questions in Education, 3(1), 35-42.

Chang, K. (2013). Factors Affecting Student Satisfaction In Different Learning Deliveries. Thesis and Dissertations. Paper 26

Clark, R., \& Voogel, A. (1985). Transfer of Training Principles for Instructional Design. Educational Communication and Technology, 33(2), 113-123.

Cormier, S. M., \& Hagman, J. D. (eds) (1987). Transfer of Learning: Contemporary Research and Applications., Academic Press Inc., San Diego.

Csikszentmihalyi, M. (1975). Beyond boredom and anxiety: The experience of play in work and games. San Francisco: Jossey-Bass.

Csikszentmihalyi, M. (1993). The Evolving Self: A Psychology for the Third Millennium, HarperCollins, New York, NY

Davachi, L., Kiefer, T., Rock, D., \& Rock, L. (2010). Learning that lasts through AGES: Maximizing the effectiveness of learning initiatives. NeuroLeadership Journal, 3, 53-63.

Doyle, W. (2006). Ecological approaches to classroom management. In C. M. Evertson \& C. S. Weinstein (Eds.), Handbook of classroom management: Research, practice, and contemporary issues (pp. 97-125). Mahwah, NJ: Lawrence Erlbaum.

Estes, C. (2004). Promoting student-centred learning in experiential education. Journal of Experiential Education, 26(2), 141-160. https://doi.org/10.1177/105382590402700203

Farrell, B., \& Farrell, H. (2008). Student satisfaction with cooperative learning in an Accounting curriculum. Journal of University Teaching and Learning Practice, 5(2), 39-54.

Felicia, P. (2011), Handbook of Research on Improving Learning and Motivation, Portland: Book News IMC

Freiberg, H. J., \& Driscoll, A. (2000). Universal teaching strategies (3d ed.). Needham, MA: Allyn \& Bacon.

Gagne, E. D., Yekovich, C. W., \& Yekovich, F. R. (1993). The Cognitive Psychology of School Learning. (2nd Edn.) New York, HarperCollins College. 
Gardner, B. S., \& Korth, S. J. (1997). Classroom strategies that facilitate transfer of learning to the workplace. Innovative Higher Education, 22(1), 45-60. https://doi.org/10.1023/A:1025151609364

Garza, A., \& Salcedo, J. (2015). Relationship Management Skills: A foundation for Successful Leadership. The Association of Leadership Educators 25th Anniversary Conference Annual Conference Proceedings, 13-18.

Gelter, H. (2010). Total experience management - a conceptual model for transformational experiences within tourism. Conference proceedings of the Nordic conference on experience 2008 (pp. 46-78). Research, Education and Practice in Media: Medusa Group of Vaasa Consortium of Higher Education, Finland: Vaasa.

Georgiou, H., \& Sharma, M. D. (2014). Does using active learning in thermodynamics lectures improve students' conceptual understanding and learning experiences? European Journal of Physics, 36(1), 015020. https://doi.org/10.1088/0143-0807/36/1/015020

Godor, B. P. (2016). Moving beyond the deep and surface dichotomy; using Q Methodology to explore students' approaches to studying, Teaching in Higher Education, 21(2), 207-218. https://doi.org/10.1080/13562517.2015.1136275

Goldstone, R. L., \& Day, S. B. (2012). Introduction to "New conceptualizations of transfer of learning". Educational Psychologist, 47, 149-152. https://doi.org/10.1215/17432197-2842457

Graham, P., Dezuanni, M., Arthurs, A., \& Hearn, G. (2015). A Dewyan experience economy for higher education. Cultural Politics, 11(1), 11-125. https://doi.org/10.1215/17432197-2842457

Grow, G. (1991). Teaching Learners to be Self-Directed. Adult Education Quarterly, 41, 125-149. https://doi.org/10.1177/0001848191041003001

Harvey, L., Burrows, A., \& Green, D. (1992). Total student experience: A first report of the QHE national survey of staff and students' views of the important criteria of quality. Birmingham, UK: QHE.

Hassanien, A. (2006). Student Experience of Group Work and Group Assessment in Higher Education, Journal of Teaching in Travel \& Tourism, 6(1), 17-39. https://doi.org/10.1300/J172v06n01_02

Hazzan, O., Lapidot, T., \& Ragonis, N. (2011). Active Learning and the Active-Learning-Based Teaching Model. In Guide to Teaching Computer Science (pp. 13-19). Springer London. https://doi.org/10.1007/978-0-85729-443-2_2

Heathers, G. (1977). A Working Definition of Individualized Instruction. Educational Leadership, 34(5), 342-345.

Hung, W. (2013). Problem-Based learning: A learning environment for enhancing learning transfer, New Directions for Adult and Continuing Education, 109, 27-38. https://doi.org/10.1002/ace.20042

Jefferson, A., Pollock, R. V. H., \& Wick, C. (2014). The Field Guide to the 6Ds: How to Use the Six Disciplines to Transform Learning into Business Results, Wiley.

Johnson, D. W., \& Johnson, R. T. (2002). Learning Together and Alone: Overview and Meta-analysis. Asia Pacific Journal of Education, 22(1), 95-105. https://doi.org/10.1080/0218879020220110

Johnson, D. W., Johnson, R. T., \& Smith, K. A. (1991). Cooperative learning: increasing college faculty instructional productivity. ASHE-ERIC Higher Education

Kagan, S. (2011). The "P" and "I" of PIES: Powerful principles for success. Kagan Online Magazine.

Keller, J. M. (1987). The systematic process of motivational design. Performance \& Instruction, 26(9), 1-8. https://doi.org/10.1002/pfi.4160260902

Knowles, M. S. (1984). Andragogy in Action. Applying modern principles of adult education. San Francisco, CA, USA: Jossey Bass.

Kolb, D. A. (1984). Experiential learning: Experience as the source of learning and development. Englewood Cliffs, NJ: Prentice Hall

Laird, D. (1985). Approaches to training and development, Reading: Mass Addison-Wesley.

Laird, T. N., Shoup, R., \& Kuh, G. (2005). Deep learning and college outcomes: Do fields of study differ? The Annual Meeting of the Association for Institutional Research, May 29 - June 1, 2005 San Diego, CA.

Leberman, S., McDonald, L., \& Doyle, S. (2006). The transfer of learning participants' perspectives of adult education and training. Aldershot, United Kingdom: Gower Publishing.

Liasidou, S. (2016). Learning and Teaching in Hotel Management Studies: Defining the Students' Experience, International Journal of Humanities and Social Science, 6(11), November, 118-128. 
Manthiou, E., Lee, S., \& Liang, T. R. (2011), "Measuring the Experience Economy and the Visitors Behavioral Consequences: An Empirical Study on Veishea Event", 16th Graduate Students Research Conference, Houston, TX, USA.

Martin, H. J. (2010). Improving Training Impact Though Effective Follow-Up: Techniques and Their Application. Journal of Management Development, 29(6), 520-534. https://doi.org/10.1108/02621711011046495

McDonald, L. (2011). Transfer of training in teacher PD A process-outcome orientation International Conference on Education and Educational Psychology (ICEEPSY 2011) Procedia - Social and Behavioral Sciences, 29(2011) 1885-1894. https://doi.org/10.1016/j.sbspro.2011.11.438

Merriam, S. B., \& Leahy, B. (2005). Learning transfer: A review of the research in adult education and training, $P A A C E$ Journal of Lifelong Learning, 14, 1-24.

Middleton, H. E., \& Baartman, L. K. J. (Eds.) (2013). Transfer, Transitions and Transformations of Learning. International Technology Education Series (Vol. 11). Rotterdam: Sense Publishers. https://doi.org/10.1007/978-94-6209-437-6

Mikulecky, L., Albers, P., \& Peers, M. (1994). Literacy transfer. University of Pennsylvania National Centre on Adult Literacy.

Miller, C. (2001). "The application of Carl Rogers' Person-Centred Learning Theory to Web- based instruction", Annual Proceedings of Selecting Research and Development, National Convention of the Association for Educational Communication and Technology, Atlanta, USA.

Moore, L. L., \& Bruce, J. A (2015). Teaching Leadership in the Experience Economy Paradigm Journal of Leadership Education, 14(4), spec. iss., 106-113.

Moore, M. G. (1989). Three types of interaction. The American Journal of Distance Education, 3(2), 1-6. https://doi.org/10.1080/08923648909526674

Nicholson, S. (2012). Completing the Experience: Debriefing in Experiential Educational Games. In Proceedings of the 3rd International Conference on Society and Information Technologies. Winter Garden, Florida: International Institute of Informatics and Systemics, 117-121.

Noblit, G. W., \& Hare, R. D. (1988). Meta-ethnography: Synthesizing qualitative studies. NewburyPark, Calif: Sage Publications. https://doi.org/10.4135/9781412985000

Olsen, R. E. W. B., \& Kagan, S. (1992). About cooperative learning. In C. Kessler(Ed.), Cooperative language learning: A teacher's resource book (pp. 1-30). Englewood Cliffs, NJ: Prentice Hall.

Perkins, D. N., \& Salomon, G. (1992). Transfer of learning. International Encyclopedia of Education, Second Edition. Oxford, England: Pergamon Press.

Pine, B. J., \& Gilmore, J. H. (1999). The experience economy: Work is theatre \&every business a stage. Harvard Business Press.

Pine, J. P. II, \& Gilmore, J. H. (1998). Welcome The experience economy: Harvard Business Review, 76(4), 97-105.

Pivec, C. R. J. (2011). Debriefing after Simulation: Guidelines for Faculty and Students. Master of Arts in Nursing Thesis. Paper 14.

Reder, L. M., \& Klatzky, R. L. (1994). Transfer: Training for performance. In D. Druckman \& R. A. Bjork (Eds.), Learning, remembering, believing: Enhancing human performance (pp. 25-56). Washington, DC: National Academy Press.

Reigeluth, C. M, Beatty, B. J., \& Myers, R. D. (Eds.) (2017). Instructional-design theories and models, Volume IV: The learner-centered paradigm of education. New York, NY: Routledge.

Reigeluth, C. M. (1999). The elaboration theory: Guidance for scope and sequence decisions. In C.M. Reigeluth (Ed.), Instructional-design theories and models: A new paradigm of instructional theory, 2, 425-453). Mahwah, NJ, US: Lawrence Erlbaum Associates Publishers.

Reigeluth, C. M., \& Stein, F. S. (1983). The elaboration theory of instruction. In C. M. Reigeluth (Ed.), Instructional-design theories and models. Hillsdale, NJ: Lawrence Erlbaum. https://doi.org/10.1007/BF00051745

Rosenshine, B. (2010). Principles of instruction. International Academy of Education.

Rosenshine, B. (2012). Principles of Instruction: Research-Based Strategies That All Teachers Should Know. American Educator, 36(1), 12. 
Royer, J. M. (1978). Theories of learning transfer, University of Illinois at Urbana Champaign Center for the Study of Reading

Salas, E., \& Cannon-Bowers, J. A. (2001). The science of training: a decade of progress, Annual Review of Psychology, 52, 471-499. https://doi.org/10.1146/annurev.psych.52.1.471

Sankar, C. S., \& Wu, Y. (2015). Design Experiential Learning Activities for MIS Introductory Courses. AMCIS.

Schoel, J., Proury, D., \& Radcliffe, P. (1988). Islands of healing. A guide to adventure based counseling. Hamilton, MA: Project Adventure,

Schwarz, R. (2005). Using facilitative skills in different roles. In R. Schwarz \& A. Davidson (Eds.), The skilled facilitator fieldbook: Tips, tools, and tested methods for consultants, facilitators, managers, trainers, and coaches (pp. 27-32). San Francisco: Jossey-Bass.

Sogunro, O. A. (2015). Motivating Factors for Adult Learners in Higher Education. International Journal of Higher Education, 4(1). https://doi.org/10.5430/ijhe.v4n1p22

Story, C. M. (1985). Facilitator of learning: A micro-ethnographic study of the teacher of the gifted. Gifted Child Quarterly, 29(4), 155-159. https://doi.org/10.1177/001698628502900403

Subedi, B. S. (2004). Emerging trends of research on transfer of learning. Intern International Education Journal, 5(4), 591-599.

Svinicki, M. D. (2004). Learning and motivation in the postsecondary classroom. Bolton, MA: Anker

Thiagarajan, (2004). Six Phases of Debriefing. Play for Performance. February, 2004. Retrieved from http://www.thiagi.com/pfp/IE4H/february2004.html

Thompson, S. E., Ngambeki, I., Troch, P. A., Sivapalan, M., \& Evangelou, D. (2012). Incorporating student-centered approaches into catchment hydrology teaching: a review and synthesis, Hydrology and Earth System Sciences, 16, 3263-3278. https://doi.org/10.5194/hess-16-3263-2012

Thomson, A., Grierson, H., Ball, P. D., \& Mendibil, K. (2008) Improving the design student experience. In: International Conference on Engineering and Product Design Education 2008, 2008-09-04-2008-09-05

Toohey, S. (1999). Designing courses for higher education. Philadelphia, PA: Open University Press.

Willingham, D. T. (2009). Why students don't like school? A cognitive scientist answers questions about how the mind works and what it means for the classroom. San Francisco, CA: JosseyBass.

Willis, J. (2007). The Neuroscience of Joyful Education, Educational Leadership, 64.

Wlodkowski, R. J. (1999). Enhancing adult motivation to learn: A comprehensive guide for teaching all adults. San Francisco: Jossey-Bass.

Wohlfarth, D., Sheras, D., Bennett, J., Simon, B., Pimental, J., \& Gabel, L. (2008). Student perceptions of learner-centered teaching. Insight. A Journal of Scholarly Teaching, 3, 67-74.

Yew, T. M., Dawood, F. K., Narayansany, K. S., Manickam, M. K. P., Jen, L. S., \& Hoay, K. C. (2016). Stimulating deep learning using active learning techniques. Malaysian Online Journal of Educational Sciences, 4(3).

\section{Copyrights}

Copyright for this article is retained by the author(s), with first publication rights granted to the journal.

This is an open-access article distributed under the terms and conditions of the Creative Commons Attribution license which permits unrestricted use, distribution, and reproduction in any medium, provided the original work is properly cited. 